\title{
TEKNOLOGI 4G-LTE DAN TANTANGAN KONVERGENSI MEDIA DI INDONESIA
}

\author{
Ilham Gemiharto \\ Program Studi Manajemen Komunikasi, Fakultas Ilmu Komunikasi, Universitas Padjadjaran
}

\begin{abstract}
ABSTRAK
Tulisan ini membahas tentang kemunculan teknologi 4G-LTE di Indonesia dan tantangan konvergensi media di Indonesia, dimana pada saat ini teknologi 4G-LTE mulai diterapkan di Indonesia, khususnya kawasan Jabodetabek sejak 2013 yang lalu. Kecepatan bandwith koneksi Internet dengan menggunakan teknologi 4G-LTE yang konon mampu mencapai 10 kali lipat kecepatan akses $3 \mathrm{G}$ mendorong penerapan konvergensi media di Indonesia. Kemunculan teknologi 4G-LTE membuka kesempatan luas bagi munculnya media-media baru di Indonesia dan memberikan tantangan untuk melakukan konvergensi media yang telah ada. Khalayak cukup memiliki satu perangkat dengan teknologi 4G-LTE untuk mengakses semua bentuk komunikasi nirkabel dan semua bentuk media massa yang ada saat ini. Tipe penelitian menggunakan interpretatif kualitatif. Fokus penelitian ini adalah analisis isi pada pemberitaan mengenai penerapan teknologi 4G LTE di Indonesia dan konvergensi media dalam kurun waktu satu tahun terakhir (November 2013 - Oktober 2014) pada media online Kompas Tekno. Teknik analisis data yang digunakan adalah metode analisis isi dengan paradigma atau pendekatan konstruksionis. Penelitian ini menggunakan pendekatan Analisis wacana model Krippendorff yang mencoba mengungkapkan nilai-nilai (values) yang berkembang dalam pemikiran pembuat teks untuk memberikan informasi atau wawasan tentang sesuatu hal yang prinsipil yang disampaikan secara tidak langsung.
\end{abstract}

Kata-kata kunci: Teknologi 4G-LTE, konvergensi media, kompas tekno, analisis isi

\section{G-LTE TECHNOLOGY AND CHALLENGES OF MEDIA CONVERGENCE IN INDONESIA}

\begin{abstract}
This paper discusses the emergence of 4G-LTE technology and the challenges of media convergence in Indonesia, where the 4G-LTE technology, especially in the Greater Jakarta area, since 2013 began to be applied. Bandwidth speed of Internet connection using 4G-LTE technology supposedly capable of reaching 10 times the speed of $3 G$ access, encourages the application of media convergence in Indonesia. The emergence of 4G-LTE technology opens vast opportunities for the emergence of new media in Indonesia and provide a challenge to existing media convergence. Audiences just need to have one device with 4G-LTE technology to access all forms of wireless communications and media that exist today. This research uses qualitative interpretative. The focus of this research is the analysis of the content of the news regarding the application of $4 G$ LTE technology and the convergence of media in Indonesia within one year period (November 2013 - October 2014) in Kompas Tekno online media. The data analysis technique used is content analysis in constructionist approach. This study uses discourse analysis approach of Krippendorff models, which tries to express the values that developed in the minds of the text producer in order to provide information or insight on principle thing conveyed indirectly.
\end{abstract}

Keywords: 4G-LTE Technology, media convergence, kompas tekno, content analysis

Korespondensi: Ilham Gemiharto, S.Sos, M.Si. Program Studi Manajemen Komunikasi, Fakultas Ilmu Komunikasi Universitas Padjadjaran, Jl. Raya Bandung-Sumedang Km.21.Email: ilham265@gmail.com 


\section{PENDAHULUAN}

Sejak memasuki milenium baru yang ditandai dengan kemunculan Internet sebagai saluran dan media komunikasi yang terus berkembang hingga saat ini, terjadi perubahan kebiasaan khalayak dalam mengonsumsi media tradisional seperti surat kabar dan radio yang semakin menurun intensitasnya. Saat ini sudah sulit menemukan suatu rumah tangga yang masih memiliki radio transistor dual band sekaligus berlangganan surat kabar harian. Sebaliknya, nyaris tidak ditemukan suatu rumah tangga tanpa kehadiran televisi dan perangkat yang memiliki koneksi Internet, seperti telepon seluler atau modem Internet. Penemuan tersebut memiliki arti bahwa kini pesaing surat kabar dan radio itu bukanlah surat kabar atau radio lainnya, namun televisi, Internet dan smartphone (telepon pintar).

Salah satu survei yang dilakukan AGB Nielsen pada tahun 2010 menemukan bahwa konsumsi khalayak terhadap surat kabar dan radio mengalami penurunan yang gradual dalam jangka waktu lima tahun terakhir, dan semakin menurun pada akhir tahun 2013. Survei tersebut sampai pada kesimpulan tren komunikasi massa saat ini menghadapi fakta bahwa time is flat while choices are multiplied, atau pilihan aktivitas semakin kompleks sementara waktu yang dimiliki oleh manusia tetap 24 jam sehari. Dalam sehari manusia menjalankan berbagai macam aktivitas, baik personal maupun sosial. Di antara berbagai macam aktivitas tersebut, hanya sebagian waktu yang digunakan untuk mengonsumsi media, apalagi media koran atau radio. Dengan kata lain, waktu yang dimiliki manusia untuk mengonsumsi media menjadi semakin terbatas. Pilihan aktivitas yang semakin kaya dengan waktu yang terbatas berujung pada tuntutan kebutuhan manusia akan media yang bersifat mudah, mobile, dan aplikatif. Manusia membutuhkan media multifungsi yang mampu melewati batas-batas ruang dan waktu, yang dapat digunakan kapanpun dan di manapun. Pada akhirnya, muncul konvergensi media sebagai teknologi media yang menjawab tantangan kebutuhan tersebut.

Teknologi LTE atau Long Term Evolution, lebih dikenal dengan sebutan teknologi 4G-LTE untuk membedakannya dengan teknologi $3 \mathrm{G}$ dan 3.5G, adalah teknologi terbaru komunikasi data nirkabel. Tujuan dari LTE adalah untuk meningkatkan kapasitas dan kecepatan jaringan data nirkabel yang telah dikembangkan pada awal milenium baru. Sistem antarmuka nirkabel 4G-LTE ini berbeda dengan jaringan $3 \mathrm{G}$ dan $3.5 \mathrm{G}$ sehingga harus dioperasikan pada spektrum yang terpisah. Koneksi Internet dengan menggunakan teknologi 4G-LTE mampu mencapai kecepatan akses data untuk mengunduh (download) hingga $300 \mathrm{Mbps}$ dan untuk menggunggah (upload) 75 Mbps.

Layanan akses data menggunakan Teknologi 4G-LTE pertama kali disediakan oleh Tella Sonera dan Ericsson di Swedia pada tahun 2009. Kecepatan akses datanya mencapai 42,78 Mbps untuk mengunduh dan 5,30 Mbps untuk mengunggah. Sejak saat itu teknologi 4G-LTE secara luas digunakan oleh berbagai negara di dunia, termasuk Indonesia. Di Indonesia, layanan akses data menggunakan teknologi 4G-LTE diluncurkan pada 14 November 2013 oleh perusahaan Internux, melalui produknya yaitu Bolt yang menawarkan kecepatan akses Internet hingga 75 Mbps. Untuk menyelenggarakan layanan teknologi 4G-LTE, Internux mengeluarkan investasi senilai 550 juta dollar AS atau sekitar Rp 6,3 triliun untuk menyewa menara BTS hingga menyediakan perangkat mobile wi- $f$ di pasar. Selanjutnya Kementerian Komunikasi dan Informatika mengeluarkan lisensi Broadband Wireless Access (BWA) dengan teknologi 4G-LTE kepada First Media, Berca, IM2, dan Jasnita, meskipun hanya diizinkan menggelar layanan data (Internet) dengan jangkauan layanan masih di wilayah Jabodetabek.

Teknologi 4G-LTE telah menjadi salah satu topik pemberitaan yang mendapat perhatian publik sepanjang tahun 2014 khususnya dalam 3 (tiga) bulan terakhir yaitu bulan Juli-Oktober 2014. Begitu pula isu mengenai konvergensi media telah begitu mengemuka di kalangan akademi dan praktisi komunikasi massa. Salah satu alasannya adalah kecepatan akses data yang dimiliki teknologi 4G-LTE media yang jauh diatas kecepatan akses data saat ini memberikan peluang yang sangat luas untuk kemunculan media-media baru dan tantangan konvergensi media bagi media yang telah ada.

Analisis penelitian dilakukan terhadap 
media online yaitu Kompas Tekno yang beralamat di www.tekno.kompas.com. Tipe penelitian menggunakan interpretatif kualitatif. Fokus penelitian ini adalah analisis isi pada pemberitaan mengenai penerapan teknologi $4 \mathrm{G}$ LTE dan konvergensi media di Indonesia dalam kurun waktu setahun terakhir pada media online Kompas Tekno. Teknik analisis data yang digunakan adalah metode analisis isi dengan paradigma atau pendekatan konstruksionis. Penelitian ini menggunakan pendekatan Analisis wacana model Krippendorff yang mencoba mengungkapkan nilai-nilai (values) yang berkembang dalam pemikiran pembuat teks untuk memberikan informasi atau wawasan tentang sesuatu hal yang prinsipil yang disampaikan secara tidak langsung.

Berdasarkan latar belakang masalah, maka terdapat masalah penelitian yang dituangkan dalam bentuk rumusan masalah sebagai berikut: (1) Bagaimana kesesuaian isi dengan fakta yang ada dalam pemberitaan yang dilakukan media online Kompas Tekno mengenai teknologi 4G-LTE dan konvergensi media di Indonesia? dan (2) Bagaimana konstruksi wacana yang dilakukan media online Kompas Tekno dalam memberitakan teknologi 4G-LTE dan konvergensi media di Indonesia?

Adapun tujuan yang ingin dicapai dalam penelitian ini adalah untuk mengetahui kesesuaian isi dengan fakta yang ada dalam pemberitaan yang dilakukan media online Kompas Tekno mengenai teknologi 4G-LTE dan konvergensi media di Indonesia dan untuk mengetahui konstruksi wacana yang dilakukan media online Kompas Tekno dalam memberitakan teknologi 4G-LTE dan konvergensi media di Indonesia.

\section{METODE PENELITIAN}

Jenis penelitian yang digunakan adalah metode analisis interpretatif kualitatif dengan pendekatan analisis wacana model Krippendorff yang mencoba mengungkapkan nilai-nilai (values) yang berkembang dalam pemikiran pembuat teks untuk memberikan informasi atau wawasan tentang sesuatu hal yang prinsipil yang disampaikan secara tidak langsung.

Fokus penelitian dimaksudkan untuk membatasi tentang apa saja yang akan dibahas dalam penelitian. Sehingga diharapkan peneliti mendapat kesimpulan yang lebih mendalam dan terfokus. Penelitian dilakukan terhadap data yang didapat sebagai data penelitian berupa pemberitaan mengenai teknologi 4G-LTE dan konvergensi media di Indonesia yang dimuat dalam media online Kompas Tekno dalam kurun waktu setahun terakhir yaitu sejak November 2013 hingga Oktober 2014.

Sumber data penelitian yaitu sumber subjek darimana data diperoleh. Atau dengan kata lain sumber data adalah sumber dimana peneliti mendapat data terkait pemberitaan mengenai teknologi 4G-LTE dan konvergensi media di Indonesia. Berdasarkan jenis penelitian, maka sumber data dalam penelitian ini adalah pemberitaan mengenai teknologi 4G-LTE dan konvergensi media di Indonesia dalam kurun waktu setahun terakhir yaitu sejak November 2013 hingga Oktober 2014. Data dikumpulkan dengan cara mengakses media online Kompas Tekno dan mengumpulkan berita terkait teknologi 4G-LTE dan konvergensi media di Indonesia.

Dalam penelitian ini jenis data yang digunakan peneliti adalah data primer berupa berita tentang teknologi 4G-LTE dan konvergensi media di Indonesia mulai November 2013 hingga Oktober 2014 dan data sekunder berupa data yang diperoleh dari situs-situs berita online (website), jurnal-jurnal komunikasi, serta buku-buku yang relevan dengan penelitian ini.

Teknik analisis data dalam penelitian ini menggunakan konsep isi yang menekankan pada penonjolan kerangka pemikiran, perspektif, dan konsep tentang memaknai pemberitaan media online Kompas Tekno tentang teknologi 4G-LTE dan konvergensi media di Indonesia mulai November 2013 hingga Oktober 2014.

Menganalisis berita pemberitaan media online Kompas Tekno tentang teknologi 4G-LTE dan konvergensi media di Indonesia mulai November 2013 hingga Oktober 2014. Data yang telah terkumpul akan dianalisis secara kualitatif yaitu dengan menggunakan metode Krippendorff yaitu digambarkan dengan kata-kata atau kalimat dengan menggunakan instrumen analisis isi dengan model melalui perangkat yang digunakan. 


\section{HASIL DAN PEMBAHASAN}

Teknologi Informasi adalah suatu teknologi yang digunakan untuk mengolah data, termasuk memproses, mendapatkan, menyusun, menyimpan, dan memanipulasi data dalam berbagai cara untuk menghasilkan informasi yang berkualitas, yaitu informasi yang relevan, akurat dan tepat waktu, yang digunakan untuk keperluan pribadi, bisnis, dan pemerintahan dan merupakan informasi yang strategis untuk pengambilan keputusan. Teknologi ini menggunakan seperangkat komputer untuk mengolah data, sistem jaringan untuk menghubungkan satu komputer dengan komputer yang lainnya sesuai dengan kebutuhan, dan teknologi telekomunikasi digunakan agar data dapat disebar dan diakses secara global.

Long Term Evolution atau yang biasa disingkat LTE adalah sebuah standar komunikasi akses data nirkabel tingkat tinggi yang berbasis pada jaringan GSM/EDGE dan UMTS/HSPA namun harus dioperasikan melalui spektrum nirkabel yang terpisah. Teknologi ini mampu mengunduh (download) hingga kecepatan 300 Mbps dan mengunggah (upload) hingga kecepatan 75 Mbps.

LTE kemudian dipasarkan dengan nama $4 \mathrm{G}$ LTE sebagai penerus jaringan 3G. LTE bahkan diklaim sebagai jaringan nirkabel yang paling cepat pertumbuhannya. LTE adalah teknologi yang didaulat akan menggantikan UMTS/HSDPA (3.5G). LTE diperkirakan akan menjadi standarisasi telepon selular secara global yang pertama. Walaupun dipasarkan sebagai teknologi 4G, LTE yang dipasarkan sekarang belum dapat disebut sebagai teknologi 4G sepenuhnya. Di Indonesia, operator pertama yang menggunakan teknologi $4 \mathrm{G}$ ini adalah Bolt yang diluncurkan oleh PT. Internux pada tanggal 14 November 2013.

Kata "konvergensi" sering digunakan untuk merujuk ke berbagai proses yang berbeda, sehingga terkadang menimbulkan kebingungan. Konvergensi media adalah penggabungan atau menyatunya saluran-saluran keluar (outlet) komunikasi massa, seperti media cetak, radio, televisi, Internet, bersama dengan teknologi-teknologi portabel dan interaktifnya, melalui berbagai platform presentasi digital. Dalam perumusan yang lebih sederhana, konvergensi media adalah bergabungnya atau terkombinasinya berbagai jenis media, yang sebelumnya dianggap terpisah dan berbeda (misalnya, komputer, televisi, radio, dan surat kabar), ke dalam sebuah media tunggal.

Gerakan konvergensi media tumbuh berkat adanya kemajuan teknologi akhirakhir ini, khususnya dari munculnya Internet dan digitalisasi informasi. Konvergensi media ini menyatukan "tiga-C" (computing, communication, dan content). Jika dijabarkan di level perusahaan, maka konvergensi ini menyatukan perusahaan-perusahaan yang bergerak di bidang informasi (komputer), jejaring telekomunikasi, dan penyedia konten (penerbit buku, surat kabar, majalah, stasiun TV, radio, musik, film, dan hiburan). Contoh yang mudah kita lihat adalah salah satu produknya, sebagai hasil perkembangan terkini pada teknologi mobile. Handphone yang Anda miliki sekarang bisa melakukan fungsi kalkulator, juga bisa untuk menonton siaran TV, mendengarkan siaran radio, membaca surat kabar online, menerima dan mengirim e-mail, memotret, merekam suara, merekam gambar video, selain tentunya untuk menelepon dan mengirim SMS.

Pengombinasianfungsi-fungsidaribeberapa piranti ke dalam satu mekanisme ini disebut juga konvergensi piranti (device convergence). Konvergensi media memungkinkan para profesional di bidang media massa untuk menyampaikan berita dan menghadirkan informasi dan hiburan, dengan menggunakan berbagai macam media. Komunikasi yang sudah dikonvergensikan menyediakan berbagai macam alat untuk penyampaian berita dan memungkinkan konsumen untuk memilih tingkat interaktivitasnya, seraya mereka bisa mengarahkan sendiri penyampaian kontennya.

Konvergensi media memungkinkan audiens (khalayak) media massa untuk berinteraksi dengan media massa dan bahkan mengisi konten media massa. Audiens sekarang dapat mengontrol kapan, di mana dan bagaimana mereka mengakses dan berhubungan dengan informasi, dalam berbagai jenisnya. Jurnalisme konvergensi melibatkan kerjasama antara jurnalis media cetak, media siar, dan media Web (online) untuk menghasilkan berita terbaik yang dimungkinkan, dengan menggunakan berbagai sistem penyampaian (delivery).

Konvergensi telah terjadi pada dua aspek 
utama: teknologi dan industri. Pada aspek teknologi, konten kreatif telah dikonversikan ke dalam bentuk-bentuk digital standar-industri, untuk disampaikan melalui jejaring pita lebar (broadband) atau tanpa-kabel (wireless), untuk ditampilkan di berbagai komputer atau piranti-piranti seperti-komputer, mulai dari telepon seluler sampai PDA (personal digital assistant), hingga ke alat perekam video digital (DVR, digital video recorder) yang terhubung ke pesawat televisi. Pada aspek industri perusahaan-perusahaan yang melintasi spektrum bisnis, mulai dari perusahaan media ke telekomunikasi sampai teknologi, telah menyatu dan membentuk aliansi-aliansi strategis untuk mengembangkan model-model bisnis baru, yang dapat meraih keuntungan dari ekspektasi konsumen yang sedang tumbuh terhadap konten media yang disesuaikan dengan permintaan (on-demand). Sejumlah analis industri memandang, konvergensi media ini menandai memudarnya "media lama" seperti media cetak dan media siar, serta bangkitnya "media baru," yang perkembangannya masih berlangsung dinamis saat ini.

Proses konstruksi realitas dalam media massa dimulai dengan adanya realitas pertama berupa keadaan, benda, pikiran, orang, peristiwa, dan sebagainya. Secara umum sistem komunikasi adalah faktor yang mempengaruhi seseorang dalam membuat wacana. Secara tidak langsung, dinamika internal dan eksternal sangat mempengaruhi proses konstruksi. Ini juga menunjukan bahwa pembentukan wacana tidak berada pada ruang vakum.

Pengaruh tersebut bisa datang dari pribadi dalam bentuk kepentingan idealis, ideologis, dan sebagainya maupun dari kepentingan eksternal dari khalayak sasaran sebagai pasar, sponsor, dan sebagainya. Menurut Fishman ada dua kecenderungan bagaimana proses produksi berita dilihat. Pandangan pertama sering disebut sebagai pandangan seleksi berita (selectivity of news). Seleksi ini berasal dari wartawan di lapangan yang akan memilih mana yang penting dan mana yang tidak penting.

Setelah masuk ke tangan redaktur, berita itu akan diseleksi lagi dan disunting dengan menekankan bagian mana yang perlu ditambah. Pandangan ini mengandaikan seolah-olah ada realitas yang benar-benar riil yang ada di luar diri wartawan. Realitas yang riil itulah yang akan diseleksi oleh wartawan kemudian dibentuk dalam sebuah berita, (Eriyanto, 2007: 100).

Asumsi dasar dalam pendekatan konstruktivis ini adalah realitas itu tidak dibentuk secara ilmiah, namun tidak juga turun karena campur tangan Tuhan. Tapi sebaliknya, ia dibentuk dan dikonstruksi. Jadi fakta merupakan konstruksi atas realitas, Kebenaran suatu fakta bersifat relatif, berlaku sesuai konteks tertentu (Eriyanto, 2002: 23).

Dengan demikian, realitas yang sama bisa ditanggapi, dimaknai dan dikonstruksi secara berbeda-beda oleh semua orang. Karena, setiap orang mempunyai pengalaman, preferensi, pendidikan tertentu dan lingkungan pergaulan atau sosial tertentu, dimana kesemua itu suatu saat akan digunakan untuk menafsirkan realitas sosial yang ada disekelilingnya dengan konstruksinya masing-masing.

Paradigma Konstruksionis memandang realitas kehidupan sosial bukanlah realitas yang natural, tetapi terbentuk dari hasil konstruksi. Karenanya, konsentrasi analisis pada paradigma konstruksionis adalah menemukan bagaimana peristiwa atau realitas tersebut dikonstruksi, dengan cara apa konstruksi itu dibentuk. Dalam studi komunikasi, paradigma konstruksionis ini sering sekali disebut sebagai paradigma produksi dan pertukaran makna. Ia sering dilawankan dengan paradigma positivis atau paradigma transmisi.

Paradigma Konstruktivisme menolak pandangan positivisme yang memisahkan subjek dengan objek komunikasi. Dalam pandangan konstruktivisme, bahasa tidak lagi hanya dilihat sebagai alat untuk memahami realitas objektif belaka dan dipisahkan dari subjek sebagai penyampai pesan. Konstruktivisme justru menganggap subjek (komunikan/ decoder) sebagai faktor sentral dalam kegiatan komunikasi serta hubungan-hubungan sosial.

Media adalah agen konstruksi. Pandangan konstruksionis mempunyai posisi yang berbeda dibandingkan positivis dalam melihat media. Dalam pandangan konstruksionis, media bukanlah sekedar saluran yang bebas, ia juga subjek yang mengkonstruksi realitas, lengkap dengan pandangan, bias, dan pemihakannya. Disini media dipandang sebagai agen Tabel 1 
Daftar Judul Berita di Kompas Tekno

\begin{tabular}{|c|c|c|c|c|}
\hline No. & Tanggal & Judul Berita & $\begin{array}{l}\text { Subjek } \\
\text { Berita }\end{array}$ & $\begin{array}{l}\text { Kategori } \\
\text { Wacana }\end{array}$ \\
\hline 1. & $\begin{array}{l}23 \text { November } \\
2013\end{array}$ & $\begin{array}{l}\text { 3G Rampung, Indonesia Sambut 4G } \\
\text { LTE }\end{array}$ & 4G-LTE & Positif \\
\hline 2. & $\begin{array}{l}14 \text { November } \\
2013\end{array}$ & 4G LTE Resmi Hadir di Indonesia & 4G-LTE & Positif \\
\hline 3. & 3 Desember 2013 & $\begin{array}{l}\text { Konvergensi, Solusi IT Tingkatkan } \\
\text { Efisien }\end{array}$ & $\begin{array}{l}\text { Konvergensi } \\
\text { Media }\end{array}$ & Positif \\
\hline 4. & $\begin{array}{l}10 \text { Desember } \\
2013\end{array}$ & $\begin{array}{l}\text { Frekuensi Lebih Rendah Lebih Baik } \\
\text { Untuk 4G LTE }\end{array}$ & 4G-LTE & Positif \\
\hline 5. & $\begin{array}{l}15 \text { Desember } \\
2013\end{array}$ & $\begin{array}{l}\text { UU Konvergensi Jangan Berpihak Pada } \\
\text { Kepentingan Bisnis }\end{array}$ & $\begin{array}{l}\text { Konvergensi } \\
\text { Media }\end{array}$ & Negatif \\
\hline 6. & 9 Januari 2014 & $\begin{array}{l}\text { Dilema Penyelenggaraan 4G-LTE di } \\
\text { Indonesia }\end{array}$ & 4G-LTE & Negatif \\
\hline 7. & 14 Maret 2014 & $\begin{array}{l}700 \mathrm{MHz} \text {, Frekuensi Emas untuk 4G } \\
\text { LTE }\end{array}$ & 4G-LTE & Positif \\
\hline 8. & 5 April 2014 & $\begin{array}{l}\text { Regulasi Konvergensi Menuju } \\
\text { Digitalisasi Informasi Disiapkan }\end{array}$ & $\begin{array}{l}\text { Konvergensi } \\
\text { Media }\end{array}$ & Positif \\
\hline 9. & 25 Mei 2014 & $\begin{array}{l}\text { Internet 4G } 700 \text { MHz Paling Cepat } \\
\text { Tahun } 2018\end{array}$ & 4G-LTE & Positif \\
\hline 10. & 26 Mei 2014 & $\begin{array}{l}\text { Kompas Gelar Gathering Konvergensi } \\
\text { Media }\end{array}$ & $\begin{array}{l}\text { Konvergensi } \\
\text { Media }\end{array}$ & Positif \\
\hline 11. & 26 Mei 2014 & $\begin{array}{l}\text { Tercengang dengan Teknologi } \\
\text { Augmented Reality }\end{array}$ & $\begin{array}{l}\text { Konvergensi } \\
\text { Media }\end{array}$ & Positif \\
\hline 12. & 2 Juli 2014 & $\begin{array}{l}\text { Pemerintah Resmi Tinjau Ulang RUU } \\
\text { Konvergensi }\end{array}$ & 4G-LTE & Negatif \\
\hline 13. & 7 Juli 2014 & $\begin{array}{l}\text { Konvergensi Media Jangan Abaikan } \\
\text { Konten }\end{array}$ & $\begin{array}{l}\text { Konvergensi } \\
\text { Media }\end{array}$ & Negatif \\
\hline 14. & $\begin{array}{l}23 \text { September } \\
2014\end{array}$ & Menjajal Kecepatan 4G-LTE di Jakarta & 4G-LTE & Positif \\
\hline 15. & 6 Oktober 2014 & $\begin{array}{l}\text { Pelaku Industri Kreatif Antusias } \\
\text { Sambut } 4 \mathrm{G}\end{array}$ & 4G-LTE & Positif \\
\hline 16. & 27 Oktober 2014 & 4G Sudah "Mengetuk Pintu” Indonesia & 4G-LTE & Positif \\
\hline 17. & 29 Oktober 2014 & $\begin{array}{l}\text { Operator Gelar 4G-LTE, yang Penting } \\
\text { Patuh Aturan }\end{array}$ & 4G-LTE & Negatif \\
\hline 18. & 30 Oktober 2014 & $\begin{array}{l}\text { 4G Juga Ditunggu untuk Kulkas dan } \\
\text { TV }\end{array}$ & 4G-LTE & Positif \\
\hline
\end{tabular}


yang menyatakan media seolah-olah sebagai tempat saluran bebas. Berita yang kita baca bukan hanya menggambarkan realitas, bukan hanya menunjukkan pendapat sumber berita, melainkan juga konstruksi dari media itu sendiri. Lewat berbagai instrumen yang dimilikinya, media ikut membentuk realitas yang tersaji dalam pemberitaan.

Pada halaman sebelumnya, dapat dilihat hasil analisis mengenai pemberitaan media online Kompas Tekno tentang teknologi 4G-LTE dan konvergensi media di Indonesia mulai November 2013 hingga Oktober 2014.

Tabel 2 Rekapitulasi Berita Mengenai Konvergensi Media

\begin{tabular}{cccc}
\hline No & $\begin{array}{c}\text { Kategori } \\
\text { Framing }\end{array}$ & Jumlah & Presentase \\
\hline 1 & Positif & 4 & $67 \%$ \\
\hline 2 & Negatif & 2 & $33 \%$ \\
\hline & Total & 6 & $100 \%$ \\
\hline
\end{tabular}

Tabel 3 Rekapitulasi Berita Mengenai Teknologi 4G-LTE

\begin{tabular}{cccc}
\hline No & $\begin{array}{c}\text { Kategori } \\
\text { Framing }\end{array}$ & Jumlah & Presentase \\
\hline 1 & Positif & 9 & $75 \%$ \\
\hline 2 & Negatif & 3 & $25 \%$ \\
\hline & Total & 12 & $100 \%$ \\
\hline
\end{tabular}

Perbandingan Proporsi pemberitaan mengenai Teknologi 4G LTE dan Konvergensi Media di atas menunjukkan bahwa secara kuantitas Teknologi 4G LTE lebih banyak diberitakan, bahkan jumlahnya dua kali lipat yaitu menjadi topik dalam 12 berita daripada pemberitaan mengenai Konvergensi Media. Isi dari keseluruhan berita mengenai teknologi 4G-LTE di Indonesia lebih kepada sisi positifnya yaitu sebanyak $75 \%$ dari total keseluruhan berita mengenai teknologi 4G-LTE. Sementara berita mengenai Konvergensi Media di Indonesia, hanya 6 (enam) berita dengan wacana positif sebanyak $67 \%$ oleh Kompas Tekno.

Media online memiliki kelebihan dalam hal kecepatan penyampaian dalam suatu artikel berita. Kelebihan tersebut memudahkan khalayak dalam mendapatkan berita teraktual, namun di sisi lain seringkali kurang memenuhi kaidah-kaidah penulisan artikel berita yang lengkap, misalnya dalam melengkapi unsur $5 \mathrm{~W}+1 \mathrm{H}$ yang menjadi syarat kelengkapan penulisan artikel berita. Hal ini terjadi dalam media online tidak ada fungsi editor, karena reporter sekaligus menjadi editor, namun kekurangan ini dapat ditutupi dengan frekuensi pemberitaan yang kontinyu bahkan masif tentang satu topik, selain itu sewaktu-waktu dapat diganti atau dihapus apabila dirasa banyak memuat kesalahan dalam penulisannya.

Berita yang dimuat Kompas Tekno mengenai 4G-LTE masih mengangkat isu mengenai kesiapan operator telekomunikasi di Indonesia menyelenggarakan layanan berbasis 4G-LTE. Meskipun layanan 4G-LTE sudah dibuka sejak tahun lalu, namun cakupannya masih sangat terbatas, yaitu hanya kawasan Jabodetabek saja. Begitu pula kualitas layanan masih belum memenuhi kecepatan yang diharapkan karena berbagai faktor seperti kondisi geografis, infrastruktur jaringan, dan regulasi dari Kemenkominfo yang hanya mengizinkan layanan teknologi 4G-LTE untuk komunikasi data saja dan bukan untuk voice call. Misalnya kecepatan tertinggi yang mampu diraih Bolt maupun First Media secara realtime masih dibawah 42 Mbps. Kemudian harga layanan juga masih terhitung mahal, yaitu 2,97 juta untuk paket Infinite.

Sementara itu pemberitaan Kompas Tekno mengenai konvergensi media masih membahas seputar Undang-Undang Konvergensi Media dan konsep konvergensi media yang paling tepat untuk diadaptasi di Indonesia. Selain itu, kendala pengadaan infrastruktur yang masih mahal menjadi kendala bagi media-media mainstream untuk melakukan konvergensi. Dengan kondisi seperti itu hanya media yang ditopang dengan struktur finansial yang kuat yang akan segera melaksanakan konvergensi.

Dilihat dari keseluruhan hasil analisis yang dilakukan, peneliti menemukan beberapa artikel berita terkait teknologi 4G-LTE dan konvergensi media di Indonesia yang dimuat pada media online Kompas Tekno memperlihatkan kekurangan dalam unsur $5 \mathrm{~W}+1 \mathrm{H}$. Masih ditemukan beberapa berita yang dimuat dengan 
hanya menggunakan satu narasumber untuk beberapa kutipan dalam satu artikel berita tanpa memerhatikan keberimbangan informasi dan data. Namun ada pula kutipan yang berbeda sudut pandang dalam berita lainnya.

Dalam artikel berita yang membahas masalah teknologi 4G-LTE dan konvergensi media di Indonesia, Kompas Tekno berusaha memuat pernyataan narasumber yang kompeten. Kompas Tekno tetap menjaga kualitas berita yang memuat kutipan dari ahli teknologi komunikasi, meskipun terkadang Tidak menyebutkan narasumber yang dikutip pernyataannya.

Jika ditinjau dari analisis isi menurut Klaus Krippendorff, dapat dilihat bahwa media mempunyai pengaruh terhadap khalayak dalam pemberitaan. Hal tersebut dikatakan sebagai agenda setting media. Secara singkat agenda setting media dapat dikatakan jika media memberikan tekanan pada suatu peristiwa, maka media itu akan mempengaruhi khalayak untuk menganggapnya penting. Jadi apa yang dianggap penting oleh media, maka penting juga bagi khalayak. Sebaliknya apa yang tidak penting bagi media maka khalayak menganggap tidak penting juga, bahkan menjadi tidak terlihat sama sekali.

Dari pengamatan yang ada, maka dapat diketahui jika Kompas Tekno telah melakukan agenda setting dalam pemberitaannya. Hal tersebut dilihat dari beberapa acuan yang meliputi penempatan dan proporsi pemberitaan, lamanya pemberitaan, isu yang sifatnya sedang hangat, sampai kepada tingkat kredibilitas media yang mengangkat isu tersebut. Namun proporsi pemberitaan merupakan aspek yang paling menonjol dalam agenda setting yang dilakukan Kompas Tekno. Porsi pemberitaan yang lebih banyak memberitakan mengenai teknologi 4G-LTE dibandingkan dengan konvergensi media di Indonesia menunjukkan bahwa Kompas Tekno ingin menggambarkan bahwa isu mengenai teknologi 4G-LTE lebih diminati khalayak daripada tantangan konvergensi media di Indonesia.

Kemudian Kompas Tekno juga seringkali mengemas judul-judul artikel berita dengan kalimat yang menarik khalayak, yang akhirnya merasa perlu untuk membaca lebih jauh isi berita. Bahkan jika berbicara lamanya pemberitaan, sejak sebelum diluncurkannya teknologi 4G-LTE pada bulan November 2013, Kompas Tekno telah memberitakan teknologi 4G-LTE sejak tahun 2010. Sementara isu mengenai konvergensi media baru diangkat sejak setahun terakhir. Hal-hal diatas telah membuktikan jika Kompas Tekno telah menganggap berita tentang penerapan teknologi 4G-LTE di Indonesia merupakan sesuatu yang penting untuk diberitakan.

Dalam pandangan kontruksionis, media bukanlah sekedar saluran yang bebas, ia juga subjek yang mengkonstruksi realitas, lengkap dengan pandangan, bias, dan pemihakannya. Begitupun dengan Kompas Tekno, dipandang sebagai agen konstruksi sosial yang mendefinisikan realitas. Jadi fakta merupakan konstruksi atas realitas, kebenaran suatu fakta bersifat relatif, berlaku sesuai konteks tertentu. Meskipun demikian realitas media yang semu tidak berlaku di pemberitaan mengenai penerapan teknologi 4G-LTE dan konvergensi media di Indonesia. Kompas Tekno tetap berusaha mengajak pembacanya untuk lebih dekat dengan realitas yang sesungguhnya.

\section{SIMPULAN}

Berdasarkan hasil analisis isi berita tentang penerapan teknologi 4G-LTE dan konvergensi media di Indonesia yang dilakukan oleh Kompas Tekno dalam kurun waktu satu tahun sejak November 2013 hingga Oktober 2014, maka dapat ditarik kesimpulan sebagai berikut:

Seperti pengalaman sebelumnya dalam penerapan teknologi $3 \mathrm{G}$ yang diluncurkan pada tahun 2003, namun mulai umum digunakan di Indonesia setelah 6 tahun kemudian yaitu pada tahun 2009. Nampaknya begitu pula dengan penerapan teknologi 4G-LTE di Indonesia. Meskipun telah diperkenalkan pada tahun 2009 di Swedia, namun nampaknya masih memerlukan waktu untuk digunakan secara luas di Indonesia. Paling tiga diperlukan 3 hingga 5 tahun ke depan untuk membangun infrastruktur teknologi 4G-LTE di Indonesia, dan memberikan layanan komunikasi berbasis 4G-LTE yang lebih terjangkau secara ekonomi.

Penerapan konvergensi media dengan menggunakan teknologi 4G-LTE masih terkendala masalah biaya yang mahal dan 
kualitas jaringan yang masih terbatas, sehingga hanya media-media dengan fondasi keuangan yang kuat yang dapat melakukannya. Selain itu praktisi media masih menanti keputusan pemerintah mengenai Undang-Undang Konvergensi.

Penentuan isi berita yang dilakukan oleh media online Kompas Tekno dilakukan dengan cara antara lain: pemilihan sumber berita, pemilihan kutipan dari sumber berita, dan menempatkan gambar yang mendukung isi pemberitaan.

Media online Kompas Tekno disengaja atau tidak telah melakukan proses agenda setting. Hal tersebut terlihat melalui cara Kompas Tekno mengangkat isu yang sedang hangat dan intensitas pemberitaannya.

Dari hasil analisis isi terlihat bahwa kebijakan media memberikan dampak pada proporsi dan intensitas pemberitaan oleh media. Hal ini menunjukkan bahwa objektivitas media dipengaruhi oleh kebijakan media.

Sesuai dengan kesimpulan diatas, maka penulis memberikan saran-saran sebagai berikut: (1) Media sebagai alat penyampaian pesan haruslah selalu menjaga agar berita selalu sesuai dengan fakta dalam menyampaikan pemberitaan, (2) Kompas Tekno sebagai salah satu media online di Indonesia harus tetap memerhatikan netralitas dan objektivitas media. Namun kaidah-kaidah penulisan artikel berita yang lengkap, misalnya kekurangan dalam melengkapi unsur $5 \mathrm{~W}+1 \mathrm{H}$ harus berusaha diperbaiki, dan (3) Dari hasil penelitian ini disarankan agar masyarakat lebih jeli dalam memaknai setiap informasi yang terkandung di dalam sebuah berita. Karena bisa saja informasi tersebut merupakan hasil konstruksi dari wartawan dan tidak sesuai dengan realitas yang sebenarnya. Pengaruh yang diterima media kadang membuat pergeseran makna yang mestinya disadari dengan baik oleh masyarakat.

\section{DAFTAR PUSTAKA}

Craig, R. (2005). Online journalism; reporting, writing and editing for new media. USA: Thomson Wadsworth.

Duhe, S. F., Mortimer, M. \& Chow, S. S. (2004). Convergence in TV newsrooms: a nationwide look, Convergence vol 10 no. 2.

Eriyanto. (2001). Analisa wacana dengan analisis teks media. Yogyakarta: LKIS. . (2002). Analisis framing: konstruksi, ideologi dan politik media. Yogyakarta: LKIS.

Krippendorff, K. (2000). Analisis isi, pengantar toeri dan metodologi. Jakarta: Utan Kayu.

Lister, D., Giddings, G., \& Kelly. (2009). New media: a critical introduction. New York: Taylor \& Francis e-Library.

Littlejohn, S. W. (1999). Theories of humam communcation. London: Wadswotrth Publishing Company.

Nurudin. (2003). Komunikasi massa. Malang: CESPUR.

Rakhmat, J. (1994). Psikologi komunikasi. Bandung: Remaja Rosdakarya.

Santana, K, S. (2005). Jurnalisme kontemporer. Jakarta: Yayasan Obor Indonesia.

Sobur, A. (2002). Analisis teks media: suatu pengantar analisis wacana, analisis semiotika, dan analisis framing. Bandung: Remaja Rosdakarya.

Uchjana, O. (2003). Ilmu, teori dan filsafat komunikasi. Bandung: Citra Aditya Bakti.

Vivian, J. (2008). Teori komunikasi massa ed.8. Jakarta: Kencana.

Wiryanto. (2005). Pengantar ilmu komunikasi. Jakarta: Gramedia Widiasarana Indonesia. 